\title{
Justification of the parameter that determines the ability of turbochargers of agricultural machinery engines to function
}

\author{
Robert Galimov ${ }^{1}$, Ilgiz Galiev 1,*, Alexander Kulakov² and Engel Galimov ${ }^{3}$ \\ ${ }^{1}$ Kazan State Agrarian University, 65, K. Marks str., Kazan, 420065, Russia \\ ${ }^{2}$ Kazan (Volga region) Federal University (Naberezhnye Chelny Institute of KFU), 13, Mira ave., Naberezhnye Chelny, 423800, Russia \\ ${ }^{3}$ Kazan Technological University named after Tupolev, 10, K. Marks str., Kazan, 420111, Russia
}

\begin{abstract}
As a result of the analysis of statistics on the main failures of the turbocharger of tractor engines in agricultural production, it can be concluded that it is the condition of its bearing node, in the first place, determines the performance of the entire turbocharger. This ultimately affects the duration of the turbocharger rotor after the engine stops. The article considers the method of determining the rotation time of the turbocharger rotor by inertia depending on the following factors: the time of the pressure drop in the turbocharger grease system, the gap in the turbocharger bearing node, the frequency of rotation of the rotor before the engine stops. The results of experimental studies on the timing of the turbocharger rotor rotation after the engine stop for the regular mode of greasing the bearing node and when using an individual lubricant system are presented. Based on the experimental values obtained, it is concluded that the main indicator of the performance of the turbocharger is the duration of rotation of its rotor after the engine stops and the application of the individual system of lubrication of the bearing node of the turbocharger reduces the cost of bearing resource and increases the resource of the entire turbocharger of agricultural machinery engines at least twice.
\end{abstract}

\section{Introduction}

Agricultural production is one of the main sectors of the country's economy, which constantly needs to attract mobile energy resources to carry out technological processes in crop and livestock production. The most promising way to meet the need for agricultural production in energy products is to increase their unit capacity $[1,2]$. In this regard, the gas turbine supercharged has found its wide use in connection with the ability to increase the single power of the internal combustion engine (by 40-50\%) without complicating its design and with almost the same mass-size parameters.

The performance of the turbocharger of the internal combustion engine, which ensures its functioning at different frequencies of rotation of the rotor, determines the reliability of the turbocharger as a whole. However, in real operation there are failures that appear as leaking oil through the seals from the turbine and compressor due to the imbalance of the rotor shaft, the seizing of the rotor shaft in the bearings of the slip due to the ingestion of oil burn products and foreign objects, the increased radial course of the rotor shaft and the ability to touch the blades of the turbine or the compressor.

The reliability of the turbocharger, first of all, is determined by the durability of the bearing node, which should ensure the performance of the turbocharger at the rotation of the rotor up to $90-100$ thousand $\mathrm{min}^{-1}$ or more.

The turbocharger is subjected to accelerated emergency wear, local overheating and failure under the influence of high dynamic and thermal loads, left without greasing and cooling, in conditions of oil starvation.

From the practice of operating turbocharger engines, it is known that the main indicators of the reliability of the turbocharger are indicators of the resource (durability) of the bearing node. The most common type of turbocharger failure is the wedge of the shaft (rotor).

Studies have shown that with increased performance, the number of failures increases, which will eventually lead to an increase in the recovery period. In this regard, research aimed at ensuring the health of systems and units, as well as tractors and agricultural machinery in general are relevant.

The performance and reliability of the equipment directly depends on the conditions and intensity of loads on the tractor engines, which are characterized by frequent and abrupt changes of modes. Increased wear and tear, reduced technical and economic performance and engine power are associated with frequent launches and long-term shutdowns of diesels, as well as short-term overloads, significant periods of acceleration and braking.

A feature of the turbocharger installed on car diesel engines is a compressor that pumps air into the cylinders of the engine, the rotation of which is carry out by the turbine. The turbine rotates from the exhaust of the engine itself, has a common shaft with a compressor and a sliding

* Corresponding author: drGali@mail.ru 
bearing. The turbocharger bearing operates under extremely negative conditions, as the exhaust temperature is $700^{\circ} \mathrm{C}$, which has an impact on the turbine and bearing. Since the oil entering the turbocharger's bearing node is involved in the grease of the rubbing elements of the entire engine, soon enough loses its quality, ensuring the reliability of the turbocharger [3].

Moreover, the turbocharger rotor develops a rotation speed from 15000 to $90000 \mathrm{~min}^{-1}$, while, structurally, there is no rigid kinematic connection with the oil pump, which leads to a long run-out of the rotor without the supply of lubricant [4]. This circumstance leads to a sharp increase in the temperature in the bearing unit, coking of the oil and accelerated wear of the bearings. One of the ways to solve the problem of improving the operational reliability of a diesel engine turbocharger is to improve the lubrication system of its bearing.

The most characteristic failures of turbochargers in real operation in agricultural production can be the flow of oil through the seals from the turbine and compressor due to the imbalance of the rotor, the sepiling of the rotor shaft in the bearings of the slip due to the ingestion of oil combustion products and foreign objects, the increased radial course of the rotor shaft and the ability to touch the blades of the turbine or the compressor. The appearance of these failures contributes to the inertial rotation of the turbocharger rotor after stopping the engine for $20 \ldots 30$ seconds. At the same time, due to the engine stop, the oil supply to the bearing unit stops within the first 5 seconds, which is accompanied by the termination of heat removal from the bearing [3]. Under these conditions, there is a sharp increase in temperature, which loses the quality of the lubricant. The amount of temperature increase depends on the operating mode of the internal combustion engine before it is stope.

Technological operations in agricultural production are associated with the presence of dynamic loads on both the machinery and its engine. In this regard, the modes of operation of the engine, and therefore the bearing node of the turbocharger, in which the unit must maintain its performance is characterized by the following modes of their operation: the start of the engine in the conditions of oil-starvation; heating the engine, winter and usually in the condition of high oil pressure in the lubricant system; a dramatic change in speed and temperature regimes; increased gap between friction pairs due to wear of the bearing, which leads to the imbalance of the rotor; a sharp drop in the oil pressure in the turbocharger bearing node due to the failure of the nodes and parts included in the lubricant system [4].

As a result of the analysis of statistics on the main failures of the turbocharger of machinery engines in agricultural production, it can be concluded that the state of its bearing node, in the first place, determines the ability to function of the entire turbocharger. This is because maintaining the stability of the turbocharger rotor is one of the main working conditions for both the bearing node and the turbocharger as a whole [5].

Based on the above, we believe that only the liquid mode of lubrication in friction pairs in all speed ranges of the turbocharger can ensure the trouble-free operation of sliding bearings. This will ensure: separation of the friction pairs of the turbocharger bearing unit with a solid oil layer; reduction of friction losses, and the absence of semi-liquid and semi-dry friction [6]. To ensure the liquid lubrication mode, the gap between the bearing and the rotor shaft of the turbocharger is provide, which increases during operation, under the influence of operating conditions.

In the process of operating the turbochargers of the machinery's engines in agricultural production, the increase in the gap in the turbocharger bearing node has an impact on its regular mode of operation, which is manifested as an increase in the movement of the open end of the rotor at rotation [7], violation of the mode of lubrication, and therefore increased wear. Ultimately, as this process progresses further, the turbine or compressor wheel may be hit on the hull and destroyed.

Since the state of the bearing unit mainly determines the performance of the entire turbocharger, it is necessary to select a state parameter from the set of parameters that change during operation, which would, by indirect values, allow us to evaluate the performance of the turbocharger. In addition, this parameter of the turbocharger state should not reduce the operational manufacturability of the entire facility.

Researchers [7] found that during operation, due to an increase in the gap in the bearing unit of the turbocharger, the duration of rotation of the rotor by inertia decreases from 35 to 7 seconds. In this regard, in our opinion, the diagnostic parameter of the state of the turbocharger is the duration of rotation of the rotor by inertia after the engine stops. It can also be assume that the longer the duration of rotation of the turbocharger rotor by inertia after the engine stops, the better the operating conditions of the bearing unit and the entire turbocharger [8].

In our further research, to determine the effect of the measures we have developed to ensure the turbocharger's operability, the duration of the rotor's rotation by inertia after the engine stops will be used as an indicator for comparing the basic version of the turbocharger's operation with the proposed one.

\section{Materials and methods}

Based on the literary analysis and the actual state of operation of the turbocharger turbochargers of the engines of the machinery in the agricultural production, it was revealed that the main factors influencing the condition of the turbocharger bearing node, and therefore the duration of the rotation of the rotor by inertia after the engine stop, are: the increase in the gap in the bearing node, the frequency of rotation of the rotor of the turbocharger before the engine stops.

The dependences of the duration of rotation of the turbocharger rotor by inertia on the above indicators can be written as:

- dependence of the turbocharger rotor run-out time after engine stop on the size of the gap in the bearing unit

$$
t_{r}=f\left(\Delta_{n}\right) \text {, }
$$


$t_{r}$ - duration of rotation of the turbocharger rotor by inertia, $\mathrm{s} ; \Delta_{n}$ - the size of the gap in the bearing unit, mkm.

- dependence of the duration of rotation of the turbocharger rotor by inertia after stopping the engine on the frequency of rotation of the turbocharger rotor before stopping the engine:

$$
t_{r}=f\left(n_{r}\right)
$$

$n_{r}$-speed of the turbocharger rotor before stopping the engine, $\min ^{-1}$;

- dependence of the duration of rotation of the turbocharger rotor by inertia on the time of pressure drop in the bearing unit to zero after the engine stops:

$$
t_{r}=f\left(t_{p}\right),
$$

$t_{p}$ - time of pressure drop in the bearing unit to zero after the engine is stopped, s.

If there are known regularities of the effect of the gap in the bearing unit, the speed of the turbocharger rotor before stopping the engine and the time of pressure drop in the bearing unit to zero after stopping the engine on the duration of rotation of the turbocharger rotor by inertia after stopping the engine, the general formula can be written as the sum of all three functions, taking into account the weight of each indicator.

The weight of the parameters "change in the clearance value in the turbocharger bearing unit", "turbocharger rotor speed before stopping the engine", "time of pressure drop in the bearing unit to zero after stopping the engine" are indicators that determine the degree of their influence on the duration of rotation of the turbocharger rotor by inertia after stopping the engine. Then the General formula for the dependence of the duration of rotation of the turbocharger rotor after the engine stops on the above parameters will look like this:

$$
t_{r}=k_{\Delta} \cdot f\left(\Delta_{n}\right)+k_{n} \cdot f\left(n_{r}\right)+k_{p} \cdot f\left(t_{p}\right),
$$

$k_{\Delta}$ - weight of the indicator changes in the gap in the turbocharger bearing unit; $k_{n}$ - weight of the rate of rotation of the rotor of the turbocharger before engine shutdown; $k_{p}$ - weight of the indicator "time of pressure drop in the bearing unit to zero after engine stop".

When finding the weights of indicators, a regression analysis should be performed. Therefore, the primary data should be present in the form of a matrix:

$$
\left(\begin{array}{ccccc}
\varphi_{11} & \varphi_{12} & \varphi_{13} & \ldots & \varphi_{1 j} \\
\varphi_{21} & \varphi_{22} & \varphi_{23} & \ldots & \varphi_{2 j} \\
\ldots & \ldots & \ldots & \ldots & \ldots \\
\ldots & \ldots & \ldots & \ldots & \ldots \\
\varphi_{i 1} & \varphi_{i 2} & \varphi_{i 3} & \ldots & \varphi_{i j}
\end{array}\right)\left(\begin{array}{c}
t_{r 1} \\
t_{r 2} \\
\ldots \\
\ldots \\
t_{r i}
\end{array}\right),
$$

$t_{r i}$ - duration of rotation of the turbocharger rotor by inertia after stopping the engine for the $\mathrm{i}$-th observation, $\mathrm{c} ; \varphi_{1 \mathrm{j}}, \varphi_{2 \mathrm{j}} \ldots \varphi_{\mathrm{ij}}$ - value of the $\mathrm{j}$-th indicator in the $\mathrm{i}-\mathrm{th}$ observation.

A regression equation of the form is output:

$$
r_{1} \cdot \varphi_{1}+r_{2} \cdot \varphi_{2}+\ldots+r_{i} \cdot \varphi_{i}=t_{r},
$$

$r_{i j}$ - regression coefficients of the $\mathrm{i}$ - th indicators.

Using equation (6), you can determine the degree of influence of each parameter $\varphi_{1}, \varphi_{2}, \ldots, \varphi_{\mathrm{i}}$ on the output indicator $t_{6}$ :

$$
k_{i}=\frac{\overline{\varphi_{i}} \cdot r_{i}}{\sum_{i=1}^{m} \overline{\varphi_{i}} \cdot r_{i}}, \sum_{\mathrm{i}=1}^{\mathrm{m}} k_{\mathrm{i}}=1,
$$

$k_{i}$ - weight of the i-th indicator; $\overline{\phi_{\mathrm{ij}}}$ - arithmetic mean of the i-th parameter.

For experimental research, a prototype of the individual system of lubrication of the turbocharger bearing node with the engine of the JMZ was made. Experiments were carried out in conditions of agricultural production. To increase the reliability of the results obtained, each indicator was measured three times and the average value was recorded. The gap in the turbocharger bearing was determined by a method that did not involve disassembling the turbocharger, which is to determine the size of the free movement of the end of the turbocharger rotor, by the formula:

$$
\Delta_{1}=\frac{h \cdot l-2 \cdot L \cdot \Delta_{2}}{2 \cdot L},
$$

$\Delta_{l}$ is the size of the gap between the rotor and the turbocharger bearing, $\mathrm{mm} ; \Delta_{2}$ is the size of the gap between the bearing and the turbocharger housing, $\mathrm{mm} ; l$ is the distance between the bearings of the turbocharger (if, constructively, provided one sleeve, then its length is taken), mm; $L$ is the shoulder length from the middle of the bearing to the end of the rotor, $\mathrm{mm}$; $h$ is free running of the end of the turbocharger rotor, $\mathrm{mm}$.

The oil pressure drop in the bearing turbocharger was carried out in manual mode, i.e. through a fixed amount of time $(90 \ldots 0 \mathrm{c})$ the crane from the hydraulic accumulator overlapped. All of measurements was carried out during the second maintenance of the vehicle, with three frequencies of rotation of the rotor of the turbocharger before the engine stop: 40,000 $\mathrm{min}^{-1}, 25,000 \mathrm{~min}^{-1}$ and $10,000 \mathrm{~min}^{-1}$. The rotational speed of the turbocharger rotor is determine and controlled by the photo-tachometer «UT 372».

To obtain a dependence describing the effect of the gap in the turbocharger bearing, the time of pressure drop in its lubrication system after the engine stops, and changes in the duration of rotation of the turbocharger rotor by inertia in dynamics, we made a sample of data on the main diagonal of the matrix of experimental indicators.

\section{Results and discussion}

In accordance with the proposed method, as a result of joint mathematical processing of changes in the gap in the turbocharger bearing, as well as the time of pressure drop in the turbocharger lubrication system after engine stop and the duration of rotation of the turbocharger rotor by inertia, dependences were obtained (rotor speed before engine stop of $40000 \mathrm{~min}^{-1}$ ):

$$
t_{r 40}=2495.71 \cdot \Delta_{n}^{-0.881} \text {. }
$$

In this case, the correlation coefficient and the error of the correlation coefficient are respectively $R_{\Delta}=0.66$, $m_{\Delta}=0.18$ [9]:

$$
t_{r 40}=28.89+6.31 \cdot t_{p}^{0,51}
$$


The correlation coefficient and the error of the correlation coefficient are respectively $R_{t}=0.62, m_{t}=0.12$ [9]. Computer calculations were performed to determine the weights of the indicators. The degree of influence of the gap in the bearing unit on the duration of rotation of the turbocharger rotor by inertia was 0.4 , the degree of influence of the time of pressure drop in the turbocharger bearing unit after engine stop on the duration of rotation of the turbocharger rotor by inertia was 0.6.

In this way, we can derive an equation of the effect of the gap and the time of pressure drop in the bearing unit of the turbocharger on the duration of rotation of its rotor by inertia (the rotor speed before stopping the engine is $\left.40000 \mathrm{~min}^{-1}\right)$ :

$$
\begin{array}{r}
t_{r 40}=0.4 \cdot 2495.71 \cdot \Delta_{n}^{-0.881}+0.6 \cdot\left(28.89+6.31 \cdot t_{p}^{0.51}\right) \\
t_{r 40}=17.33+1038.28 \cdot \Delta_{n}^{-0.881}+3.78 \cdot t_{p}^{0.51} .
\end{array}
$$

The dependences of the effect of the gap and the time of pressure drop in the turbocharger bearing unit on the duration of its rotor rotation by inertia at the rotor speed before stopping the engine $25000 \mathrm{~min}^{-1}$ and $10000 \mathrm{~min}^{-1}$ were also obtained:

$$
\begin{array}{r}
t_{r 25}=\frac{109.1+6.98 \cdot t_{p}}{1,34+0,049 \cdot t_{p}}- \\
-\frac{\Delta_{n} \cdot\left(2.02+0.074 \cdot t_{p}-0.01 \cdot \Delta_{n}-0.0004 \cdot \Delta \cdot t_{p}\right)}{1,34+0,049 \cdot t_{p}} \\
t_{r 10}=2.62+5.83 \cdot t_{p}^{0.41}+2554.88 \cdot \Delta_{n}^{-1.491},
\end{array}
$$

Assessment of prediction quality is reduced to checking the adequacy of calculated and actual indicators. The adequacy of the obtained dependences was check by comparing the actual value of the duration of rotation of the turbocharger rotor by inertia on another car that did not participate in the experiment with the calculated values. The deviation of the calculated and actual values of the duration of rotation of the turbocharger rotor by inertia did not exceed $3.5 \%$. With the normal bearing lubrication mode and the initial speed of the turbocharger rotor at $40000 \mathrm{~min}^{-1}$, during operation, the run-out time varies from 65.3 to 48.3 seconds. This is due to the fact that the time of pressure drop in the normal mode of turbocharger bearing lubrication after the engine stops is within 4 ...6 seconds, then within 60 seconds the rotor rotates without any lubricant.

During this period, the temperature in the bearing unit rises sharply, which causes a complete loss of oil viscosity and the appearance of semi-dry friction. In addition, a sharp increase in temperature causes coking of the oil. Also, it should be noted that due to the presence of a common turbocharger lubrication system with the engine, over time, the quality of the lubricant decreases, which leads to increased wear of the turbocharger bearing.

When using an individual lubrication system for the turbocharger bearing unit and the initial speed of the TCR rotor of $40000 \mathrm{~min}^{-1}$, during operation, the run-out time varies from 91.9 to 87.9 seconds. This is due to the presence of a hydraulic accumulator in the design of the turbocharger lubrication system, which provides oil supply for 90 seconds after the engine stops, and an individual lubrication system involves providing the turbocharger bearing unit with high-quality lubricant.

The same conclusions are made for the values of the duration of rotation of the turbocharger rotor by inertia at the speed of its rotation before stopping the engine of $25000 \mathrm{~min}^{-1}$ and $10000 \mathrm{~min}^{-1}$.

\section{Conclusion}

The main indicator of the performance of the turbocharger of the internal combustion engine of the techniques in agricultural production is the duration (time) of rotation of its rotor by inertia after the engine stops.

Using the presented dependencies, you can calculate the duration of rotation of the turbocharger rotor by inertia for the normal lubrication mode and when using an individual lubrication system for the turbocharger bearing unit.

Evaluation of the prediction quality is reveal by comparing the calculated and actual values of the duration of rotation of the turbocharger rotor by inertia, which shows that the calculated values are adequate to the actual ones. The deviation of the calculated and actual values of the duration of rotation of the turbocharger rotor by inertia did not exceed $3.5 \%$.

Based on the obtained experimental values, it can be seen that the use of an individual lubrication system for the turbocharger-bearing unit reduces the resource consumption of the bearing and increases the resource of the entire turbocharger at least twice.

\section{References}

1. M.H. Fashutdinov, K.A. Khafizov, I.G. Galiev, F.Z. Gabdrafikov, F.H. Khaliullin, BIO Web Conf., 17, 00056 (2020)

2. K.A. Khafizov, R.N. Khafizov, A.A. Nurmiev, I.G. Galiev, BIO Web Conf., 17, 00022 (2020)

3. A.S. Denisov, A.A. Korkin, Improving the technologies and organization of ensuring the operability of machines, pp. 21-27 (Saratov, 2010)

4. M.G. Kruglov, A.A. Mednov, Gas dynamics of combined internal combustion engines (Mashinostroenie, 1988)

5. A.M. Plaksin et al., Fundamental Research, 6, 728732 (2014)

6. G.M. Savelyev, B.F. Lyamtsev, E.V. Aboltin, Experience in the development and production of turbochargers for automobile engines (Institute of excellence for automotive industry executives and professionals, Moscow, 1986)

7. B.S. Stechkin, Theory of heat engines. Selected works (Nauka, 1977)

8. A.I. Kolchin, V.P. Demidov, Calculation of automobile and tractor engines (Higher School, 1980)

9. O.P. Krastin, Methods of analysis of regressions and correlations (CSU SM of the Latvian SSR, 1970) 